\title{
The Reform of Teacher Education at the University of New Brunswick: Why and How?
}

\author{
Mark Hirschkorn \\ University of New Brunswick
}

Alan Sears

University of New Brunswick

Sharon Rich

University of New Brunswick

\begin{abstract}
In the fall of 2008, the Faculty of Education at the University of New Brunswick implemented its 'new' Bachelor of Education program. This was precipitated by a number of factors including pressure from the education community in New Brunswick, streamlining due to declining faculty numbers, and a drive to incorporate recommendations drawn from recent teacher education literature. Two of the changes made were: (a) the program is now completed in 1 year (formerly 2 years); (b) education students complete a one year practical component at the same time they complete their on campus components. The article concludes with some implications for faculty at other institutions who may be asking themselves - are they ready to make changes in their programs?
\end{abstract}

Keywords: teacher education, program reform, professional learning communities

Mark Hirschkorn is an assistant professor in the Faculty of Education at the University of New Brunswick. His research areas are teacher education reform, teacher induction and professional development and inquiry-based science education practices. Email: mhirschk@unb.ca

Alan Sears is a professor in the Faculty of Education at the University of New Brunswick. His research areas are citizenship education, educational policy and teacher education.

Sharon Rich is a professor and Dean at the Faculty of Education, University of New Brunswick. Her research interests include virtual teaching and learning, learning communities and literacy education.

Brock Education, Volume 18, No. 2, Spring 2009, 81-95 


\section{The Reform of Teacher Education at the University of New Brunswick Why and How?}

In the fall of 2008, the Faculty of Education at the University of New Brunswick (UNB) implemented its 'new', reworked, Bachelor of Education (B.Ed.) program. This moment was highly anticipated by faculty as well as the education community in the province of New Brunswick (UNB graduates more teachers than all of the other education institutions in the province combined) and was years in the forging. In this article, we begin with a discussion of the context that led to changing the B.Ed. program at UNB. This is followed by a description of the reconceptualization process; what aspects of research were incorporated and how the NB educational community was included in the re-envisioning process. Third, we offer a brief overview of the teacher education program that resulted including a discussion of how the new program is different than the program it replaced and why. There is then a short description of the methodology being used to study the new program in addition to early findings from the program review research implemented alongside the new program. The article concludes with some implications for faculty at other institutions that may be asking themselves - are they ready to make changes in their programs? We recognize that other teacher education institutions in Canada are struggling with reform issues of their own and we intend our work to contribute to the wider conversations about the preparation of beginning teachers.

\section{Context: Why a New Education Program at UNB?}

In early 2006 the Faculty of Education at UNB undertook a significant revision of its B.Ed. program. At that point the faculty was offering a 60 credit hour B.Ed. program that could be pursued either consecutively (following a first undergraduate degree) or concurrently (in combination with another undergraduate degree). The program was extremely flexible with multiple entry points and a range of routes through the requirements. For example, consecutive students might enter the program in September or January and concurrent students might enter after completing the first, second, or third year of their other degree. The program was originally designed to provide a 15 week internship followed by one term back at the university. The intent was to focus reflections on this immersion in teaching in the context of previous academic and professional education. However, many students planned their programs so as to complete all required course work before the internship. They thus left the program without the opportunity for structured reflection on their teaching practice. Additionally, provincial course requirements coupled with faculty members' individual interests and passions led to the creation of courses that were often only loosely connected to what is required for teacher accreditation. The result was over 178 courses listed in the teacher education program, excluding the field experiences. Although the faculty had attempted to organize courses around core studies and related subject methodology, the proliferation of courses and the numbers of options available made it difficult to maintain coherence. The result was a range of pragmatic, pedagogical and theoretical concerns combining to force a rethinking of the faculty's programs. We believe UNB's particular circumstances were characteristic of larger trends and issues facing teaching and teacher education across Canada and elsewhere. These include: 


\section{The Continuing Evolution of Faculties of Education as Sites of Research and Knowledge Production Related to Education in Addition to Being Institutions Primarily Responsible for Initial Teacher Education.}

In 1973, following a trend set earlier in Central and Western Canada, New Brunswick saw the integration of its teachers' colleges into universities as faculties or departments of education (Chan, Fisher \& Rubenson, 2007). This created a shift not only in the location of teacher education but in the expectations of faculty members who were now seen not only as teacher educators but also as researchers and scholars. Overall, UNB faculty members responded well to the new expectations with the Faculty moving up considerably over the years on the University's internal research ranking exercise.

This change in role, however, also poses several challenges to teacher education including a more limited direct role of tenure stream faculty in the enterprise (particularly the field based-components) as they focus more on research and graduate teaching. There is also often a sense of disconnect from the field as faculty are perceived to be focusing on more general and theoretical concerns while ignoring the development of applied teaching skills and specific provincial policies. At UNB theses concerns were first filtered back to the faculty in terms of anecdotal evidence from internship supervisors and other contacts between faculty members and colleagues in the field. However, a large-scale survey of new graduates, cooperating teachers and school administrators conducted by the Department of Education (DoE) produced devastating results for the faculty. The survey targeted the three English language B.Ed. programs in New Brunswick and one from the University of Maine that provided most of the new teachers hired in the province. UNB's program was regarded as least effective in virtually every area by a significant degree. In particular, our students were perceived as not having a common background of knowledge and skills in teaching and learning generally and were also considered relatively weak in a number of areas including: specific techniques for teaching literacy; the capacity to differentiate instruction for students at a range of academic ability levels; classroom management skills; and knowledge of provincial policies and curricula. Although there were problems with the survey instrument and many faculty members contested the often narrow, functional and non-theoretical nature of the concerns raised, there was no doubt that the poor perception of the faculty was widespread and a threat to ongoing positive and professional relationships with partners in the field.

\section{Significant Shifts in Understandings of Teaching as a Profession and the Role of the Profession in the Education and Induction of New Members.}

Chan, Fisher and Rubenson (2007) argue that a key component of evolving teacher professionalism is growing professional autonomy including a role for the profession in preservice education and professional induction. Ungerleider (1994) points out that the creation of a College of Teachers in British Columbia "gave teachers control over entry to the profession, the preparation of its members, and the judgment of their competence" (p. 375). Even in jurisdictions without Colleges of Teachers, there has been "a shift from a view of schools as bureaucratic organizations to one of schools as professional learning communities" (Williams, Brien, Sprague \& Sullivan, 2008, p. 2) including responsibility for inducting and mentoring new members of the profession.

Consistent with this changing view of the profession's role in the preparation of new members, a range of recent scholarship in teacher education argues for teacher education 
programs "to consider how they can engage in partnerships with schools and districts that work to transform schooling and teaching in tandem" (Bransford, Darling-Hammond \& LePage, 2005, p.5). Unfortunately, practice in the faculty of education at UNB seemed a considerable departure from that ideal. The DoE survey demonstrated that teachers and administrators in New Brunswick felt a significant degree of disconnection between themselves, their schools and the UNB Faculty of Education. Declining faculty numbers meant internship supervision was provided more often by non-faculty supervisors so that there was significantly less actual faculty presence in schools. However, the problem was greater than a lack of direct contact. Teachers and school administrators indicated they felt they had virtually no input into teacher education at UNB and that interns were being assigned to them with poorly articulated expectations and little support from university supervisors. On the other hand, university supervisors often felt schools worked to undermine the program by telling students some version of, "you can forget all that theory you learned at the university: this is the real world." Again, reported perceptions on both sides represented a slanted description of faculty-school relations but there was no doubt these perceptions, regardless of accuracy, were both genuinely felt and a significant problem for the success of the program.

\section{The Perpetual Struggle to Link Theory and Practice in Teacher Education}

In his seminal work on communities of practice Wenger (1998) argues, "With respect to newcomers, it may be better to intersperse moments of information sharing and reflection with moments of peripheral engagement in practice than to 'front-load' all the classroom training and call that 'learning"' (p. 250). On this view opportunities for professional practice and classroom learning/reflection would be closely connected and recursive. Where to place teaching practice in a program and how to integrate with university-based experiences, is a perennial issue for faculties of education everywhere. At UNB there was a significant sense of disconnection noted by students and some faculty between course work and the internship. Part of the reason for this was the lack of regular faculty involvement in internship supervision for reasons discussed above. The situation was exacerbated by the growing trend to leave the internship to the end of the program. Unintentionally, we had fallen into just the practice Wenger warned against and by front-loading all the classroom learning we had established weak connections between opportunities for professional practice and in class reflection.

While the particular problems that gave rise to the reconsideration of our B.Ed. program were specific to our own institutional and provincial context the underlying issues are ones faced by faculties of education everywhere: fostering the development of faculty members as researcher and scholars while maintaining their participation and influence in initial teacher preparation; recognizing the growing role of the profession and professional bodies in teacher education; and linking theory and practice in recursive and mutually beneficial ways. As we considered our old program in light of these trends it was clear we were a long way from fostering the professional learning communities advocated both by the province and in a range of literature on teacher professionalism (Wenger, 1998; Darling-Hammond, \& Bransford, 2005).

\section{Toward a Collaborative Approach to Reform}

With these issues in mind the process of framing a new approach to pre-service education at UNB was begun. From the beginning we saw collaboration as a central imperative both in terms of how we would work toward reform and the purpose of the reform itself. In other words, we 
were committed to collaborating so that the resulting program would foster better professional collaboration. We understand this collaboration to be multidimensional, recursive and persistent. It is multidimensional in the sense that collaboration will be going on at a number of levels and in various sites. As important as communities of practice are to professional learning, Wenger (1998) points out that if they become too insular they can actually reify poor practice and stifle reflection and reform. It is important to recognize, he writes, that "communities of practice cannot be considered in isolation from the rest of the world, or understood independently from other practices" (p. 103). In teacher education a number of communities of practice are at play including university faculty members, teachers in schools, and the B.Ed. students themselves (not to mention other possibilities such as adjunct faculty often hired to supervise field experiences but not really included in the faculty community of practice). We were committed to fostering "boundary practices" (Wenger, 1998, p. 114): that is, setting up situations where members crossed boundaries and engaged with colleagues in the other communities. These practices can disrupt taken for granted assumptions on all sides and foster significant growth.

Our approach is recursive in the sense that ideas for reform flowing from collaboration, and especially the cross-boundary work described above, will flow in all directions. This is not just about reforming teacher education at UNB but about school reform more generally. We are hoping our collaboration with colleagues across the education sector in New Brunswick will shape our program in positive ways but also help foster thinking and reflection about their own practice: perhaps opening up new possibilities for collaborative scholarship and research in schools unrelated to the B.Ed. program. We want to build not only a new undergraduate teacher education program but also "constellations of interconnected practice" (Wenger, 1998, p. 127) among the faculty, teacher interns and school partners. This broader vision is consistent with recent work in teacher development, which calls for teacher education programs "to consider how they can engage in partnerships with schools and districts that work to transform schooling and teaching in tandem" (Bransford, Darling-Hammond \& LePage, 2005, p. 5).

Finally, our work is persistent in the sense that it is ongoing. The partnerships we are establishing with teachers, schools and school systems will stay in place and not only serve to run the program, but to reflect on and reshape the program as well. In his recent book on educational reform, Levin (2008) argues that too often educational reforms are rushed into place based on little or no evidence and then abandoned just as quickly when spectacular results are not immediately evident or when the political climate changes. He argues for a much more tempered approach to reform that would include ongoing monitoring of initiatives, reflection on both data collected and the experiences of participants, and revisions as necessary. Reform in teacher education often follows the pathological pattern described by Levin: reforms almost never include systematic monitoring of progress and feedback to those involved. We believe the partnerships established to reform and implement our new B.Ed. program can be used effectively as part of the ongoing monitoring and revising of it as well. The work described in this paper is a first attempt at that.

With these principles in mind we set out to build intersecting communities of practice. We engaged our educational partners very early in the process. Research indicated that the best collaborative relationships among faculties of education, school districts and schools include crucial elements such as "a collegial and egalitarian relationship among participants" and "partnership center[ed] around a genuine problem or issue to be solved" (Lefever-Davis, Johnson \& Pearman, 2007, pp. 204-205). Before that consultation could begin, however, the faculty established some key parameters and principles - the theoretical model by which the program 
was guided. Shulman's (1987) work on content knowledge, Darling-Hammond's (2000) work on the integration of classroom and clinical experiences, and the Association of Canadian Deans of Education ACCORD (2006) list of principles for more coherent, cohesive programs that meet the needs of teachers and students, were keystones in the drafting of the parameters. The following is the list of the parameters and principles with which the Steering Committee began:

(a) The program would extend over 11 months beginning in late August and ending in midJuly.

(b) The program would include three compulsory core courses: Introduction to Teaching and Learning; The Social Context of Education; and Inclusionary Practices.

(c) Field experiences would be contained within the Introduction to Teaching and Learning course and would be a carefully structured set of experiences designed to move newcomers from the periphery to the core of the professional community; to help them develop what Wenger calls an "inbound trajectory." These experiences should provide "an approximation of full participation and can take various forms such as "lessened intensity, lessened risk, special assistance, lessened cost or error, close supervision, or lessened production pressures" (Wenger, 1998, pp. 100-101).

(d) A professional learning community's model would be central to the development of the program. A central theme from the program feedback discussed above is that people were largely working in isolation and any sense of community within the faculty, among interns or between the faculty and its educational partners was largely absent. With Sfard (1998) we recognized that professional learning "is now conceived of as becoming a member of a certain community" (p. 6) and we were determined to create an overlapping set of professional learning communities within the program. For this reason we made a fundamental change to the way interns would be assigned. Rather than assigning them to individual teachers, the interns would be assigned to a school with a 'school liaison' acting to coordinate the in-school experiences of the interns. Through this we hoped to foster a sense of school staff as a professional learning community, rather than individual teachers. We also hoped that the team of interns assigned to a school would themselves develop as a professional learning community. This would also provide the school some flexibility to fine tune the field experience; to take into consideration the interpersonal and pragmatic 'realities' of placing teaching interns in schools. Several faculty members had experience with fostering the professional growth of learning communities both in the context of student teaching and wider professional practice. We drew on this expertise in establishing our new approach (Whitty, 1996; Kristmanson, Dicks, Bouthillier, \& Bourgoin, 2008). Additionally, the faculty committed to the principle that university supervisors would become part of the professional learning communities of the schools in which they worked. We wanted to develop and sustain a substantial partnership with our colleagues in the field to support our mutual work in teacher education.

In establishing this framework we were cognizant of Wenger's (1998) contention that professional communities function best as sites of learning when there is the right degree of creative tension between reification and participation. Reification, or the setting out of explicit policies and procedures, is necessary because it gives shape and consistency to professional practice, but an emphasis on it alone can squelch growth and contribute to the stagnation of practice. Wenger argues that members of a community of practice must be able to participate in shaping and reshaping policies and practices if the community is to be a dynamic site of professional learning and growth. In Wenger's terms the recommendations set out here establish 
a reified framework for the UNB Faculty of Education's revised B.Ed. program and we believed them to be a solid basis for beginning extensive consultation with colleagues from the public education community. It was recognized however, that the parameters needed to remain malleable while reconceptualising the program: during our consultations leading up to finalizing of the new program; and after its implementation.

With the assistance of a grant from the UNB Teaching and Learning Fund, in November 2006 we began extensive consultations with educational partners in New Brunswick. The first step was a two-day meeting between faculty members and 50 representatives from various sectors of public education in the province, nominated by the DoE and the New Brunswick Teachers' Association (NBTA). Our work together included plenary sessions where representatives of the NB educational community set out their concerns about teacher education and representatives of the Faculty presented the draft framework for the new program. There were also several opportunities for small group and large group discussion and interaction.

From that initial meeting, a Steering Committee was formed that included representatives from the Faculty and the various educational partners. Members of the committee from the field included teachers, principals, school district supervisors and superintendents, in addition to representatives from the DoE and the NBTA. The committee met for full day meetings four times between January and May 2007. Our partners responded enthusiastically to the initial framework and worked hard to help flesh out program components based around the principles listed above. There were, of course, a number of substantive issues that were debated and logistical threats to the new program debated. Space does not allow full consideration of those here but discussion of them is contained in the report prepared by the Steering Committee and approved by Faculty Council. The ground work for the new program had been established.

\section{The Plan: A Characterization of the New Education Program}

This program seeks to unify the students' experiences with respect to course content and school practica; to have these components contribute to and depend on each other. It is also designed to create learning communities comprised of both school and university personnel; to change the nature of school-university collaboration to a reciprocated partnership in which each partner benefits from the insights and expertise of the other. From a students' experiential perspective, however, the program is driven by their timetable, what is expected of them, and when. It is from this perspective that we describe the new program. Dewey (1938) considered experience to be the means through which educational processes work, hence an understanding of education requires an appraisal of the kind of experience individuals have.

After receiving their acceptance letter (that includes information on the assigned school for the practica), the students' education program begins with a 2-Day Introductory Seminar in mid-August. During this orientation, students receive an overview of the program (including the practica), meet the other students placed at their schools, are introduced to professional portfolios and Danielson's (2007) four Domains of Professional Practice - the backbone of their teaching and professional development assessment. Additionally, because these interns are in the schools immediately after the 2-day seminar, they are introduced to the Code of Professional Conduct for New Brunswick teachers in addition to policies and issues concerning teaching as a profession.

The following week, students begin a two week Initial Practicum in which they report to their assigned school, are introduced to key personnel such as the administrative team, the school liaison and teachers who work in the areas in which they have an interest, and generally assist in the start up period of a school. They attend professional development sessions along with their 
teacher colleagues, prepare materials and classrooms alongside teachers in their fields, and are there on the students' first day to welcome them to the school year and their new classes. These interns are not teachers yet, but have begun the process of participating in the start-up behaviours of classroom teachers; experiences that many of the old program interns did not have.

Following the 2-week initial practicum, the interns begin their Novice Practicum, and their role shifts. On Mondays each week, interns return to their schools and a schedule created by the liaison teacher for exposure to a range of classroom contexts, teachers, and teaching styles. It is hoped that the intern is directed toward experiences that build on and reinforce the topic discussed that week on campus, and that they are an active participant in the teaching environment in which they find themselves. During the novice practicum, interns also attend classes at the university Tuesday through Friday to engage in course work. The three core courses offered during these four days were designed to present topics that align with their school experiences and ask the students to use these experiences to respond and connect to the topics being covered from a more informed and personal perspective. For example, one of the earlier topics is 'organizing the learning environment' - which corresponds to teachers' activities at the beginning of the school year. Thus, the students are asked to reflect upon their practicum experiences as each topic is presented in the Introduction to Teaching and Learning course. Students have a number of other optional and subject specific courses that round out their schedules each week by proceeding courses intended to provide the specific teaching strategies and pedagogical theories they will encounter as subject or Elementary specialists. The structure of the novice practicum leads students to complete courses while drawing upon and embedding their own classroom experiences. This block culminates in an intermediate practicum in November-December.

The Intermediate Practicum begins in the third week of November and is three weeks long. At this point interns are assigned to a specific teacher (ideally in pairs) to promote collaboration and support. This experience moves interns gradually from a support and observation role into a teaching role; this is a gradual transition that is incremental and encourages reflection, and is operatively defined for the intern, the students and the mentor teacher as keeping everyone "safe". The emphasis at this stage is not on the quantity of teaching but on a variety of specific classroom experiences.

In the New Year, interns return to a Monday in the schools, Tuesday to Friday on-campus format, with similar intentions and priorities as described in the novice practicum. Interns continue to relate course topics to their in-school experiences, culminating in a 7-week advanced practicum.

The Advanced Practicum begins in April. By this point interns should be well aware of the culture of their school, have built many relationships with the teachers and the students in the school, and are expected to be prepared and ready to teach. Here each intern experiences the full range and intensity of teaching activities and carries full teaching responsibilities for a minimum of fifty percent of the time. Although interns will continue to draw upon the support and feedback of their peers, this practicum stresses opportunities for each intern to shine as an individual in the classroom.

The program concludes with a two month on-campus component in which students are asked to reflect upon their teaching experiences and the resources/materials they have collected throughout the practica. For example, the interns fine tune their professional portfolios and turn their attention toward practical concerns such as finding teaching positions and additional professional development oriented topics such as what it means to be a teaching professional. 
This period is also unique in that the interns are given the opportunity to reflect upon their placements (their teacher experiences) in the context of an informed and receptive group of peers.

There will be variances in every student's experience with the new program depending on context, background, motivation, nature and many other factors. As such, it is at times difficult to implement a program that meets the specific expectations and needs of each intern. It is also recognized that a program of this nature needs to remain responsive to the many stakeholders influenced by the program. This list includes the student, school personnel, the DoE, and university personnel influenced by the new program. Toward this end a program review has been established that actively seeks the opinions, experiences and feedback of the stakeholders or participants influenced by the new education program. The next section will give a brief overview of the methodology used to study the new program. It is our intention in a follow-up article (Part 2 in a series of three articles) to give a more detailed description of the program review research itself, what has been learned in the process of doing the research, and to make recommendations for other institutions that wish to study their teacher education programs.

\section{Overview of Methodology}

In 2008 a research team of three faculty members applied for and received funding and research ethics approval to conduct a three year study on the impact and effectiveness of the newly implemented B.Ed. program at UNB. Since the research is a program review, fundamentally, the research focus is: How effective is the new teacher education program at preparing teachers for NB schools? Casey \& Childs (2007) point out that this is an important (but not easy) question to ask when they recommend that research needs to be done that asks if beginning teachers are experiencing success in their first few years of practice, and what factors influence the likelihood of that experience. Data on the impact of specific components of the new program are being collected by soliciting qualitative, experiential feedback/insights from the participants in four ways. First, an anonymous and secure website has been set up to allow all participants to login and offer their feedback on their experiences. Second, each member of the research team is immersed within the new program and is documenting feedback received from participants anonymously and anecdotally (what we have labelled as the 'ears \& eyes' stage). This includes research notes on interviews with individual participants. Third, focus groups of randomly selected participants are held at the end of each semester to discuss the experiences of the participants in the program and to make recommendations for changes that would be a 'better' alternative to the current program design. Fourth, follow-up surveys will be sent to graduates one and two years after graduation, in addition to the individual interviews of randomly selected graduates at that time. Data will be analyzed using a recursive and emergent grounded theory approach.

As alluded to previously, the participants in the research reviewing the new program encompass anyone who is influenced by, or who influences the program. At this stage the participants have been grouped into three broad categories; students, school personnel and university personnel (see Table 1 for a list of participants that make up each participant category). 
Table 1

Participant Groupings

$\underline{\text { Students }}$

Preservice education students

Graduated education students
School Personnel

Mentor Teachers

Liaison Teachers

School Administration

District Administration
University Personnel

Faculty Representatives

Tutorial Instructors

Faculty

Field Services

Support Staff

Deans

In the next section we will describe some of the early feedback from the participants that provide a glimpse into the reception and perception of the program three months into its inaugural year. The intention for doing this is to provide a glimpse of what is being learned by studying the new program - a glimpse that in our opinion indicates the potential and value of doing this research. However, the data is still being collected and there has been no formal data analysis done that could act as a basis for definitive conclusions or generalizations. There is a brief discussion of the implications of this article for other teacher educators which follows.

\section{The Early Results: The Participants Speak}

Crocker and Dibbon (2008) quoted Fullan's (2001, p. 247) description of Collaborative enterprises between faculties and schools/districts can serve as inschool laboratories for nurturing teaching and learning, action research on authentic problems of practice, testing innovative approaches, collecting and analyzing evidence, and an extensive continuum of development for new teachers in a program driven by the practical needs of the sites and districts involved. Such reciprocal relationships are characterized as arrangements whereby "schools become just as committed to teacher education as they are to school improvement; and universities become just as committed to school improvement as to teacher education". (p.115)

This quote exemplifies how the new program at UNB seems well suited to address recommendations for teacher education programs Canada wide. Any new program provides a unique opportunity to learn from the process and reflect on the effectiveness of the various intentions that make up the program - in this case, intentions distilled from the educational research as well as the educational community in New Brunswick.

Not surprisingly, the insights and feedback received from each participant varies, but there already seems to be patterns in the feedback received from each of the categories of participants. For example, students tend to focus on issues of cost and workload, school personnel tend to discuss scheduling and communication, whereas university personnel tend to address administrative issues. At this juncture, however, data is still being collected and a formal data analysis remains to be done, thus it is not appropriate to frame a discussion of the results around 
the participant groupings, or the relative 'success' of the program components. What follows is a summary of early patterns that are emerging from the data.

\section{Feedback, Empowerment and Human Nature}

Anecdotally, there has been more positive feedback about the new program than criticism, but the positive feedback tends to be more diffuse and undirected (as compared with negative feedback). For example, comments such as "really liked", "got a lot out of the two week practicum at the beginning", "it is going well", or even "everything is going well, why would I take the time to offer feedback?" have been made and represent a large, seemingly silent majority that is appreciating and benefitting from the program but largely go unrecorded. Examples of the negative feedback are discussed later in this section. Interestingly, it appears that because it was made clear to the participants (particularly the students and school personnel) that there is a research project reviewing the new program, this has empowered the participants to have opinions and question the structure of the program more than they might otherwise. Unlike many other experiences in life in which a person "toughs it out" because there is no feedback mechanism or simply because "you have to" - we have seemingly given the participants the willingness to question the program. This is good from a feedback perspective, but has this also decreased the willingness of the participants to fight their way through hardship?

\section{Shadows of the Past}

Putting the reputation of the old education program at UNB amongst the education community in New Brunswick aside for the moment, there is an expectation for how practica and education programs in general "work" - a historical norm if you will. What has been observed, in the schools in particular, is that many 'old practicum' patterns are re-emerging in the absence of knowing explicitly what the alternatives are. Examples include:

(a) Schools do not know how to "use" the university and its personnel as a member of a learning community.

(b) Interns are assumed to have much more background in pedagogic content knowledge than should be expected (remember they are in the schools prior to taking any university education classes) - because that is what previous student teachers have had. Similarly, some interns are being asked to teach lessons because "that is what other interns have done".

(c) Comparisons with other education programs is inevitable in a province this size, and because some of the other programs have begun their full-time internships, while UNB's education students at this point have been limited to two weeks at the beginning and few Mondays, UNB students are not seen as advanced as other students.

(d) A keystone of the new program was to provide as much flexibility for the schools as possible - to create experiences for the interns under broad topic headings, but to leave it to designated liaison teachers to direct the interns. However, traditionally schools have been told quite explicitly "what to do". In the absence of this top-down, "do as I tell you" model - some school personnel have expressed uncertainty regarding the university's expectations. This is perhaps exacerbated by the relative inexperience of the university 
representatives in the schools with the new program expectations (they too are more familiar with the old, top-down model).

\section{Administrivia}

The old program used a semester system, with clear distinctions between practica and course work on campus. With the advent of the new program crossing semesters and embedding the practica within course work, it created difficulties for the registrar's office as they tried to make it fit within their existing administrative system. Thus there were many instances in the first month of the program in which the students and schools were asked to be patient as the schedules (and paperwork) were worked out on a student by student, school by school basis. This created frustrations for all concerned, not the least of which, for the staff doing the paperwork. It also served as a reminder for how closely budgeted the finances of students are - last minute requests for "practica fees" weeks after the other fees were described and asked for were not well received.

On a related note, because this is the inaugural year for the new program, the preparation for courses and practica, particularly by university faculty, continued until the last minute. As a result, the intended immersive dependency and collaboration between the on-campus components was not fully realized. Faculty members were frustrated in their preparations by the relative reticence of other faculty to have their planning at a stage in which it could be shared and built upon. It is expected that these problems will diminish greatly in future years of the program as the faculty members gain a better sense of how topics are broached by their colleagues, and how more extensive collaboration might occur.

\section{Work, Work, Work}

Many students report feeling overwhelmed with the workload required of them within the education program. Some students (and faculty) believe it is a function of two years of material being compressed into a single year by faculty. Others believe it is the poor communication among faculty regarding due dates for major assignments. Still others believe it is due to the shorter week, and the time and energy it takes to immerse themselves in the schools every Monday - time and energy they traditionally would direct toward completing course requirements. Whatever the cause, there is an overwhelming amount of data stemming from the students that points to what has been described as "ridiculous work and reading requirements being given to the students". A few of the students have suggested that faculty clarify how much work is collectively being asked of the students and to consider how to modify the expectations for each course to allow students time to complete and reflect upon their experiences.

\section{Tabula Rasa?}

Some members of the education community (members of the DoE, schools and school districts) in New Brunswick have indicated they are gratified to see the changes to the education program and believe the changes to be a significant improvement over the old program; that they are motivated to work with faculty and students - even though they had openly criticized the program in the past. A truism of universities and schools in general is not whether an allegation is true, it is whether it is believed to be true - one clear message that has been stated is that the 
faculty of education at UNB has been granted the benefit of the doubt with the advent of the new program. Even though the slate may not have been wiped entirely clean, the changes to the B.Ed. program have kindled a hopeful optimism in the education community regarding the program. Individuals that had refused to work with the education faculty and program at UNB in the past have reopened themselves to that possibility. This revitalized willingness is an indication of the potential of the program, and how it was conceived and implemented. It also conveys the importance of working to realize the potential of the program, the importance of research designed to inform the success and challenges of the program, and allowing it to evolve and grow according to the insights of the New Brunswick education community and the educational research.

\section{Conclusion}

Throughout the conception and implementation process of the new teacher education program at UNB, two things were maintained. First, it was understood that we were not creating final solutions for many of the issues that plagued our old program or that plague other teacher education programs. Program improvement is a recursive and ongoing process. Incorporating changes, assessing program effectiveness, and the evaluation and improvement of our teacher education program has continued after its implementation date. Second, it was deemed vital to include the educational community in the creation of the program, and to remain sensitive to the opinions and experiences of this community once the program had begun. This program review research and the dissemination of the findings is one way in which we are endeavouring to do so.

The factors driving UNB toward reform (changing roles for faculty members; greater demands from the profession for a role in teacher education and ongoing attempts to better integrate theory and practice) impact virtually every faculty of education in some way. We believe our experience might prove valuable to others as they attempt to work out solutions in their own contexts. This article is our attempt to offer readers a window into how we are attempting to address these issues; to widen conversation around the context that led up to the decision to reform the UNB teacher education program; and to provide a brief description of the program setting and the practices upon which it is currently being employed. It is hoped that by sharing our context and circumstances with other teacher educators we are inviting them to consider how their own contexts may be similar and different to UNB, and to perhaps gain some insights into how they may approach teacher education reform in their own institutions.

Kathy Winslow and Ruth Forsythe

\section{Acknowledgements}




\section{References}

Association of Canadian Deans of Education (2006). ACCORD on Teacher Education. Retrieved September 01, 2006 from http://www.csse.ca/CADE/TeacherAccord.pdf

Bransford, J., Darling-Hammond, L., \& LePage, P. (2005). Introduction. In L. DarlingHammond \& J. Bransford (Eds.), Preparing teachers for a changing world: What teachers should learn and be able to do (pp. 1-39). San Francisco: Jossey-Bass.

Casey, C., \& Childs, R. (2007). Teacher education program admission criteria and what beginning teacher need to know to be successful teachers. Canadian Journal of Education Administration and Policy, 67, 1-23.

Chan, A. S., Fisher, D., \& Rubenson, K. (Eds.). (2007). The evolution of professionalism: Educational policy in the Provinces and Territories of Canada. Vancouver: University of British Columbia, Centre for Policy Studies in Higher Education and Training.

Crocker, R., \& Dibbon, D. (2008). Teacher education in Canada. Kelowna, BC: Society for the Advancement of Excellence in Education.

Danielson, C. (2007). Enhancing professional practice: A framework for teaching (2nd ed.). Alexandria, VA: Association for Supervision and Curriculum Development.

Darling-Hammond, L. (2000). Teacher quality and student achievement: A review of state policy evidence. Education Policy Analysis Archives, 8(1). Retrieved September 01, 2006 from http://epaa.asu.edu/eppa/v8n1

Darling-Hammond, L., \& Bransford, J. (Eds.). (2005). Preparing teachers for a changing world: What teachers should learn and be able to do. San Francisco: Jossey-Bass.

Dewey, J. (1938). Experience and Education. New York: MacMillan.

Kristmanson, P., Dicks, J., Le Bouthillier, J., \& Bourgoin, R. (2008). Exploring the teaching of writing through a professional learning community. Education Canada, 48(3), 37-39.

Lefever-Davis, S., Johnson, C., \& Pearman, C. (2007). Two sides of a partnership: Egalitarianism and empowerment in school-university partnerships. Journal of Educational Research, 100(4), 204-210.

Levin, B. (2008). How to change 5000 Schools: A practical and positive approach for leading change at every level. Cambridge, MA: Harvard Education Press.

Sfard, A. (1998). On two metaphors for learning and the dangers of choosing just one. Educational Researcher, 27(2), 4-13.

Shulman, L. S. (1987). Knowledge and teaching: Foundations of the new reform. Harvard Educational Review, 57(1), 1-22. 
Ungerleider, C. (1994). Power, politics, and the professionalization of teachers in British Columbia. In L. Erwin \& D. MacLennan (Eds.), Sociology of Education in Canada (pp. 370-379). Toronto: Copp Clark Longman.

Wenger, E. (1998). Communities of practice: Learning, meaning, and identity. Cambridge, U.K.: Cambridge University Press.

Whitty, P. (1996). Academic wisdom and practical action. Learning for the workplace: Nordic and Canadian Perspectives. Finland: Department of Education.

Williams, R., Brien, K., Sprague, C., \& Sullivan, G. (2008). Professional learning communities: Developing a school level readiness instrument [Electronic Version]. Canadian Journal of Educational Administration and Policy. Retrieved December 21, 2008 from http://www.umanitoba.ca/publications/cjeap/pdf_files/williamsspraguesullivanbrien.pdf 